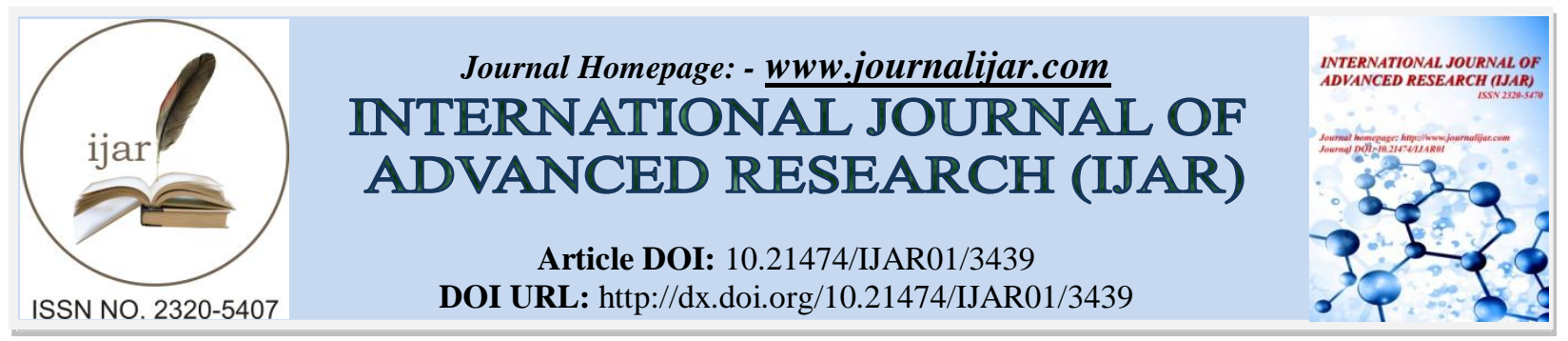

RESEARCH ARTICLE

\title{
RETINITIS SECONDARY TO RIFT VALLEY FEVER : CASE REPORT AND REVIEW OF LITERATURE.
}

\author{
Maryam M. Al Omar MD ${ }^{1}$, Malak A. Bamashmoos MD ${ }^{1}$ and Sanaa A. Yassin MD ${ }^{2}$. \\ 1. University of Dammam. \\ 2. King Fahad University Hospital.
}

\section{Manuscript Info}

Manuscript History

Received: 11 December 2016

Final Accepted: 16 January 2017

Published: February 2017

Key words:-

Rift valley fever, ocular manifestations, review of literature

\begin{abstract}
A 64 year-old Saudi gentleman, originally from Gazan (southwestern region) of Saudi Arabia presented with history of decrease vision in the right eye for 25 years. Patient gave history of Rift Valley fever (RVF) 25 years ago, that nictitate his admission to the hospital for one week. He described right eye vision worsening after suffering from fever. Fundus of the right eye showed hypertrophic black chorioretinal adjacent to an atrophic scar in the macula, and the left eye showed defuse retinal pigment epithelial (RPE) mottling.

This case report aims to present the sequelae of retinitis secondary to RVF with brief review of literature of ophthalmic complications of RVF. Ocular involvements in RVF are found in up to $20 \%$ of the cases. It may include retinal hemorrhages, anterior uveitis, vitreous reactions and macular edema and retinitis.
\end{abstract}

Copy Right, IJAR, 2017,. All rights reserved.

\section{Introduction:-}

Rift valley fever (RVF) is an acute viral zoonotic febrile disease that caused by a virus related toBunyaviridaeFamily. It affects cattle, sheep and humans ${ }^{1,2}$. The disease transmitted to human by bits of infectedmosquito or direct exposure to infected animals' tissues ${ }^{1,3}$.Disease presentation ranges from mild, selflimited to sever form with hemorrhagic, ocular, meningoencephalitis complications ${ }^{4}$. Symptoms ofRVF starts after the incubation period (2days to 1 week) as flu like symptoms with headache, photophobia, joint pain, retro-orbital pain and myalgia ${ }^{1,5}$. Sever cases, $7-8 \%$ will develop hemorrhagic syndromes, meningo-encephalitis and death. Ocular complications occur in $1-20 \%$ of them².

Ocular manifestation may include: retinal hemorrhages, anterior uveitis, vitreous reactions, optic disc edema, and retinal vasculitis. Macular and paramacular edema also could develop ${ }^{6,7}$. The first reported epizootic RVF outbreak was in Kenya 1930, since that year epidemics was spread through Africa until 2000 when the outbreak reaches southwestern region of Saudi Arabia and Yemen as a first epidemic outside Africa ${ }^{2,7-8}$.This case report aims to present the sequelae of retinitis secondary to RVF with brief review of literature of ophthalmic complications of RVF.

\section{Case presentation:-}

A 64 year-old Saudi gentleman, originally from Gazan (southwestern region) of Saudi Arabia presented with history of decrease vision in the right eye for 25 years. Patient gave history of Rift Valley fever (RVF) 25 years ago, that 
nictitate his admission to the hospital for one week. He described right eye vision worsening after suffering from fever. He is not known to have any medical illness.

He underwent cataract surgery for the right and left eyes 3 years and 1 year back, respectively.

\section{On examination:-}

He had visual acuity of 0.16 in the right eye and 1.0 in the left eye.

Slit lamp examination showed pseudophakia in both eyes with no posterior capsular opacification (PCO).

Fundus of the right eye showed hypertrophic black chorioretinal adjacent to an atrophic scar in the macula, and the left eye showed defuse retinal pigment epithelial (RPE) mottling as shown in figure 1-2.
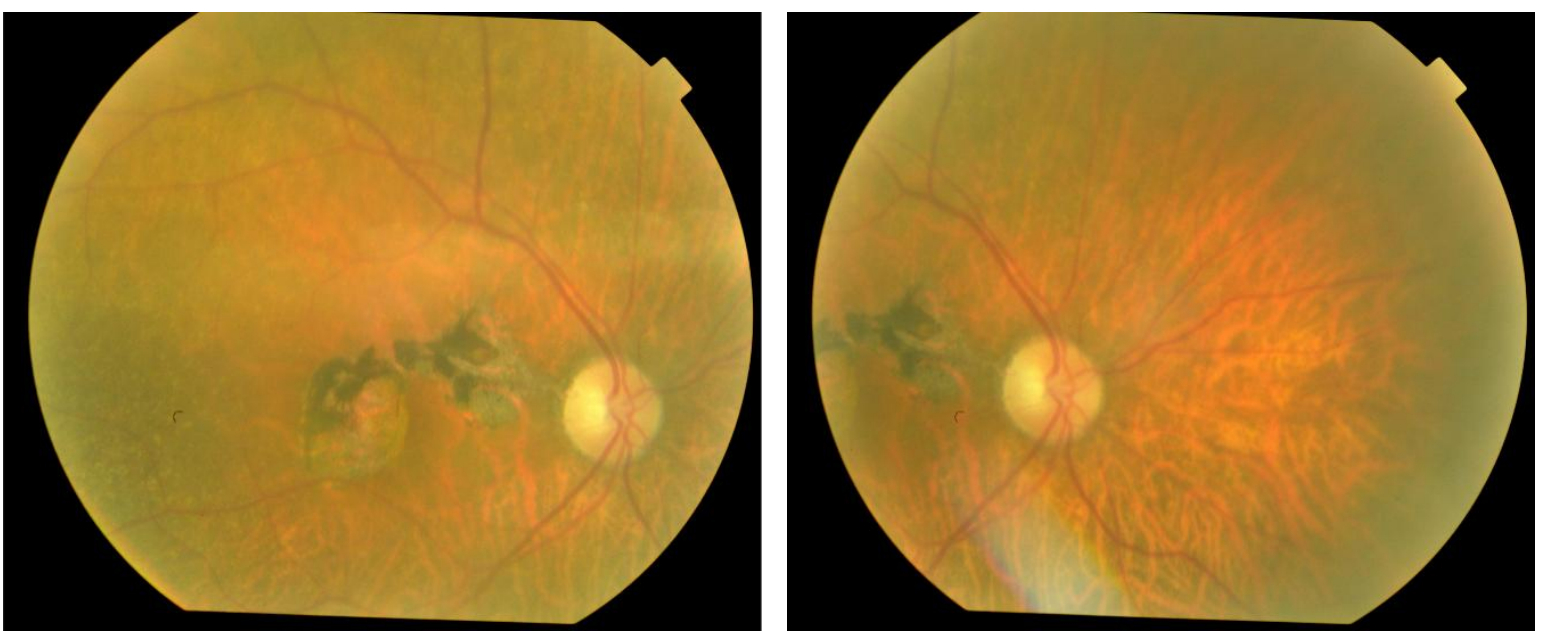

Figure 1:- fundus photograph of the right eye showingatrophicmacular scar.
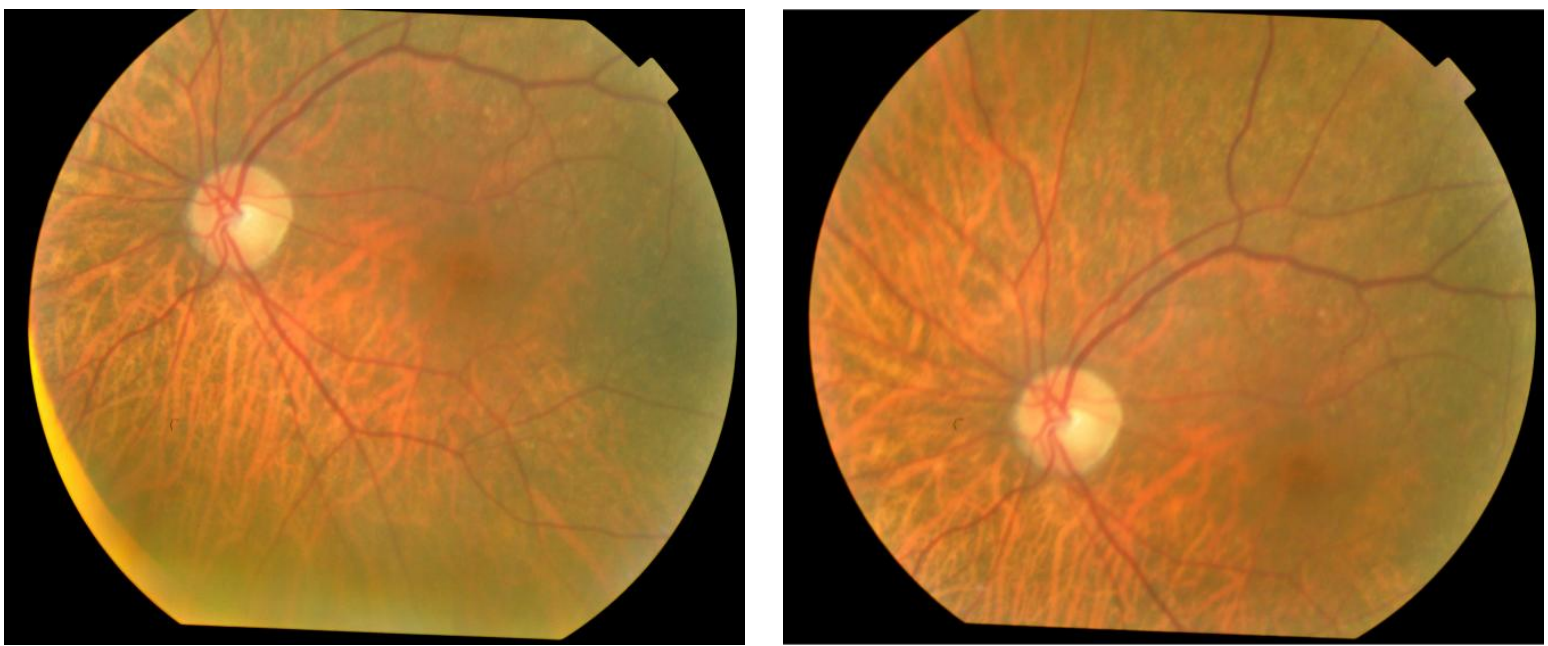

Figure 2:- fundus photograph of the left eye showingretinal pigment epithelial mottling.

\section{Discussion:-}

Rift valley fever (RVF) is a viral zoonotic disease from the family of Bunyaviridaethat affect both animals and humans ${ }^{1}$. Humans acquire the infection from bites of infected mosquitoes or through direct exposure to body fluid or tissues of infected animals ${ }^{1}$. The first epizootic outbreak of Rift valley fever was reported in kenya in $1930^{2}$.

Affected individuals usually have mild, self-limited disease, lasting few days but sever disease with ocular, hemorrhagic, meningoencephalitis complications can occur ${ }^{7}$. Ocular manifestations accounts for up to $20 \%$ of cases ${ }^{8}$.It was estimated that $1 \%$ of RVF cases have ocular complications during Gazan epidemic ${ }^{8}$. Ocular lesions usually develop within 4 weeks after the onset of illness. The pathogenesis of the lesions as suggested by fluorescein 
angiography indicates that the lesions often start with primary occlusion of the retinal circulation, probably as a result of proliferation of the virus particles on the endothelial cells ${ }^{2}$. Before 1977, RVF caused mild disease in human and ocular complications were less frequent. In contrary, it was found that ocular complications were higher during Egypt outbreak ${ }^{3}$.The most common ocular presentation was macular and paramacular retinitis as found in several studies ${ }^{3,8}$. It was found during Gazan epidemic that macular retinitis accounts for $71 \%$ while paramacular retinitis accounts for $29 \%{ }^{8}$. Retinitis can present alone or in association with other ocular abnormalities ${ }^{3}$. Anterior uveitis was reported first during Gazan epidemic. It was characterized by mild-moderate non-granulomatous type that resolved without any complication such as cataract, glaucoma or posterior synechiae ${ }^{3}$. Retinal hemorrhages occurred in $40 \%$ of cases, vasculitis was seen in $7 \%$, vitreous reaction in $27 \%$ were seen along with retinitis. Optic nerve edema seen in $15 \%^{3}$.

The natural course of the disease depends upon the severity and the location of the retinal abnormality. Visual acuity may completely recover, with minimal loss of visual field, or there may be severe and permanent loss of vision, such as occurs in persistent total retinal detachment ${ }^{2}$. The most common complication was retinal scaring. Other complications include vascular occlusion leading to retinal ischemia and disc atrophy ${ }^{3,8}$.

In conclusion, retinitis is the most common ocular complication in RVF outbreak in Gazan, Saudi Arabia. Many studies recommend that Saudi Arabia and other Middle East countries have to sit a comprehensive strategy to prevent RVF recurrence.

\section{References:-}

1. MoncefK,SoonPhaik C, Sivakumar R, Rathinam, Sonia A, Venu N. Novel infectious agents causing uveitis. Springer 2009; 30: 465-483 Available from: http://link.springer.com/article/10.1007\%2Fs10792-0099319-6 doi:10.1007/s10792-009-9319-6

2. Deutman AF, Klomp HJ. Rift Valley fever retinitis. Am J Ophthalmol.1975; 92( 1):38

3. Al-Hazmi A1, Al-Rajhi AA, Abboud EB, Ayoola EA, Al-Hazmi M, Saadi R, et al. Ocular complications of Rift Valley fever outbreak in Saudi Arabia. American Academy of Ophthalmology.2005; 112( 2): 313-318 Available from: http://www.aaojournal.org/article/S0161-6420(04)01490-3/abstract DOI: http://dx.doi.org/10.1016/j.ophtha.2004.09.018

4. El MamyA, Baba M, Barry Y, Isselmou K, L. Dia M, Ba Hampate, et al. Unexpected Rift Valley fever outbreak, northern Mauritania.Emerg Infect Dis. 2011; 17( 10): 1894-1896 Available from: https://www.ncbi.nlm.nih.gov/pmc/articles/PMC3310676/doi: 10.3201/eid1710.110397

5. CDC. Outbreak of Rift Valley Fever-Saudi Arabia, August-October, 2000. October 13, 2000 / 49(40);905-8. Available from: http://www.cdc.gov/mmwr/preview/mmwrhtml/mm4940a1.htm

6. Al-Hazmi M1, Ayoola EA, Abdurahman M, Banzal S, Ashraf J, El-BushraA,et al. Epidemic Rift Valley fever in Saudi Arabia: a clinical study of severe illness in humans.Clin Infect Dis.2003; 1;36( 3): 245-52 Available from: http://cid.oxfordjournals.org/content/36/3/245.longdoi: 10.1086/345671

7. Charles D. Ericsson, Robert Steffen. Viral hemorrhagic fever hazards for travelers in Africa. Clin Infect Dis.2003; 33( 10): 1707-1712. Available http://cid.oxfordjournals.org/content/33/10/1707.longdoi: 10.1086/322620

8. Siam AL, Meegan JM, Gharbawi KF. Rift Valley fever ocular manifestations: observations during the 1977 epidemic in Egypt. $\mathrm{Br} \quad J$ Ophthalmol. 1980 May; 64( 5):366-346 Available from: https://www.ncbi.nlm.nih.gov/pmc/articles/PMC1043698/ 